\title{
Evaluation of Stiffness of the Spastic Lower Extremity Muscles in Early Spinal Cord Injury by Acoustic Radiation Force Impulse Imaging
}

\author{
Kang Hee Cho, MD, Jin Hee Nam, MD \\ Department of Rehabilitation Medicine, Chungnam National University School of Medicine, Daejeon, Korea
}

Objective To investigate intrinsic viscoelastic changes using shear wave velocities (SWVs) of spastic lower extremity muscles in patients with early spinal cord injury (SCI) via acoustic radiation force impulse (ARFI) imaging and to evaluate correlation between the SWV values and spasticity.

Methods Eighteen patients with SCI within 3 months and 10 healthy adults participated. We applied the ARFI technique to measure SWV of gastrocnemius muscle (GCM) and long head of biceps femoris muscle. Spasticity of ankle and knee joint was assessed by original Ashworth Scale.

Results Ten patients with SCI had spasticity. Patients with spasticity had significantly faster SWV for GCM and biceps femoris muscle than those without spasticity (Mann-Whitney $U$ test, $p=0.007$ and $p=0.008$ ) and normal control ( $\mathrm{p}=0.011$ and $\mathrm{p}=0.037$, respectively). The SWV values of GCM correlated with the ankle spasticity (Spearman rank teat, $\mathrm{p}=0.026$ ). There was significant correlation between the SWV values for long head of biceps femoris muscle and knee spasticity (Spearman rank teat, $\mathrm{p}=0.022$ ).

Conclusion ARFI demonstrated a difference in muscle stiffness in the GCM between patients with spastic SCI and those without spasticity. This finding suggested that stiffness of muscles increased in spastic lower extremity of early SCI patients. ARFI imaging is a valuable tool for noninvasive assessment of the stiffness of the spastic muscle and has the potential to identify pathomechanical changes of the tissue associated with SCI.

Keywords Muscle spasticity, Spinal cord injuries, Ultrasonography

Received July 30, 2014; Accepted October 27, 2014

Corresponding author: Jin Hee Nam

Department of Rehabilitation Medicine, Chungnam National University Hospital, 282 Munhwa-ro, Jung-gu, Daejeon 301-721, Korea

Tel: +82-42-338-2460, Fax: +82-42-338-2461, E-mail: shapil21@naver.com

(a) This is an open-access article distributed under the terms of the Creative Commons Attribution Non-Commercial License (http://creativecommons. org/licenses/by-nc/4.0) which permits unrestricted noncommercial use, distribution, and reproduction in any medium, provided the original work is properly cited.

Copyright $\odot 2015$ by Korean Academy of Rehabilitation Medicine

\section{INTRODUCTION}

Spasticity is generally conceptualized as a symptom of the upper motor neuron lesion. It is characterized by an exaggeration of the stretch reflex, spasms and resistance to passive movement across a joint, secondary to the hyperexcitability of spinal reflexes [1-6]. A complete loss of descending corticospinal projections is rare in patients with clinical signs of spasticity after spinal cord injury (SCI). Preserved propriospinal and supraspinal input to a given segmental level may explain why spasticity is a 
frequent consequence in SCI [1]. One hypothesis on the pathophysiology of spasticity highlights the important role of long-term reductions in segmental inhibition rather than primary increases in excitation.

Precise evaluation of spasticity is crucial to establish the efficacy of medical and physical therapeutic interventions. Various diagnostic methods are available to investigate specific influences of spasticity on muscles. The most obvious diagnosis of spasticity is based on the clinical assessment of muscle tone by a physician or physiotherapist, such as the Original Ashworth Scale (AS) [5] and the Modified Tardieu Scale. Spasticity has a neural component that is evoked by a velocity-dependent phenomenon. It also has a biomechanical component, such as soft-tissue compliance, i.e., stiffness [6]. Many studies showed that stiffness increased in spastic muscles due to changes in fiber type transformation. Morphometric and histochemical investigations show changes in mechanical muscle-fiber properties that might contribute to spastic muscle tone [7-12]. Changes in biomechanical conditions of a muscle might also have an important effect on the spasticity in people with SCI.

Acoustic radiation force impulse (ARFI) imaging utilizes ultrasound elastography technology, hence it is an ideal tool to noninvasively estimate the clinical field tissue stiffness. ARFI is achieved by mechanically exciting tissues with a localized impulsive radiation force. This results in shear wave propagation away from the region of excitation [13]. Shear wave velocity (SWV) is directly correlated with tissue stiffness. In general, greater SWV correlates with stiffer tissue. ARFI imaging has been used to study a variety of tissues, including liver [14], breast [15], kidney [16], spleen [17], prostate [18], pancreas [19], testes [20], thyroid [21], and muscle and tendon [22]. The most notable application of ARFI is the detection of liver fibrosis [23,24], because the fibrous tissues are usually stiffer than the surrounding tissues [25]. However, there is a lack of ARFI application to the spasticity of musculoskeletal tissues.

The aim of this study was to investigate intrinsic viscoelastic changes using SWV of spastic lower extremity muscles in patients with early SCI via ARFI and to evalu-

Table 1. Characteristics of groups A and B

\begin{tabular}{|c|c|c|c|c|c|c|c|}
\hline & $\begin{array}{c}\text { Patient } \\
\text { no. }\end{array}$ & Sex & $\begin{array}{l}\text { Age } \\
\text { (yr) }\end{array}$ & $\begin{array}{c}\text { AIS } \\
\text { score }\end{array}$ & $\begin{array}{l}\text { Time since } \\
\text { injury (mo) }\end{array}$ & $\begin{array}{l}\text { AS score of ankle } \\
\text { plantar flexor }\end{array}$ & $\begin{array}{l}\text { AS score of } \\
\text { knee flexor }\end{array}$ \\
\hline \multirow[t]{10}{*}{ Group $A^{\text {a) }}$} & 1 & $\mathrm{M}$ & 49 & $\mathrm{C}$ & 2.3 & 1 & 2 \\
\hline & 2 & M & 72 & $\mathrm{C}$ & 2.1 & 2 & 2 \\
\hline & 3 & F & 55 & $\mathrm{C}$ & 3.5 & 1 & 1 \\
\hline & 4 & M & 22 & $\mathrm{C}$ & 2.1 & 1 & 3 \\
\hline & 5 & F & 75 & $\mathrm{D}$ & 3.2 & 0 & 1 \\
\hline & 6 & M & 72 & $\mathrm{C}$ & 1.5 & 2 & 1 \\
\hline & 7 & F & 50 & $\mathrm{D}$ & 2.0 & 2 & 1 \\
\hline & 8 & F & 62 & $\mathrm{C}$ & 3.3 & 1 & 1 \\
\hline & 9 & F & 50 & $\mathrm{C}$ & 2.2 & 2 & 3 \\
\hline & 10 & M & 49 & $\mathrm{D}$ & 2.1 & 2 & 2 \\
\hline \multirow[t]{8}{*}{ Group B $^{\text {b) }}$} & 1 & M & 52 & $\mathrm{C}$ & 1.1 & 0 & 0 \\
\hline & 2 & M & 74 & $\mathrm{C}$ & 2.2 & 0 & 0 \\
\hline & 3 & F & 52 & $\mathrm{D}$ & 2.3 & 0 & 0 \\
\hline & 4 & M & 22 & $\mathrm{D}$ & 1.2 & 0 & 0 \\
\hline & 5 & F & 55 & $\mathrm{D}$ & 3.2 & 0 & 0 \\
\hline & 6 & M & 68 & $\mathrm{C}$ & 2.5 & 0 & 0 \\
\hline & 7 & M & 47 & $\mathrm{C}$ & 3.3 & 0 & 0 \\
\hline & 8 & F & 50 & $\mathrm{D}$ & 1.2 & 0 & 0 \\
\hline
\end{tabular}

AIS, American Spinal Injury Association impairment scale using the International Standards for Neurological Classification of Spinal Cord Injury; AS, original Ashworth Scale.

${ }^{a)}$ Patient with spinal cord injury and spasticity. ${ }^{\text {b) }}$ Patient with spinal cord injury and no spasticity. 
ate correlation between the SWV values and spasticity.

\section{MATERIALS AND METHODS}

\section{Subjects}

Eighteen patients undergoing rehabilitation treatment after having finished the acute stage of treatment for SCI were recruited. This study was limited to subjects with cervical spinal injury. Disease duration was within 3 months in all included patients since the focus of the study was early intrinsic viscoelastic changes of spastic lower extremity muscles in patients with SCI. Patients were divided into 2 groups, group A (mean age, 53.6 \pm 22.7 years; 5 males, 5 females; mean height, $163.7 \pm 9.1 \mathrm{~cm}$; mean weight, $62.4 \pm 8.26 \mathrm{~kg}$ ) included patients with spasticity and group B (mean age, $52.5 \pm 15.5$ years; 5 males, 3 females; mean height, $167.7 \pm 12.1 \mathrm{~cm}$; mean weight, $64.9 \pm 11.2 \mathrm{~kg}$ ) included patients without spasticity (Table 1). Exclusion criteria were 1) previous botulinum toxin type A injection to the medial gastrocnemius muscle (GCM) or the long head of the biceps femoris muscle (BFLH), 2) fixed ankle or knee contracture, or 3) previous surgery of the lower limbs. Ten healthy adults without neurologic or musculoskeletal disabilities were included as a control group (group C; mean age, $42.7 \pm 14.2$ years; 6 males, 4 females; mean height, $170.8 \pm 6.21 \mathrm{~cm}$; mean weight, $66.9 \pm 8.1 \mathrm{~kg}$ ) (Table 2).

Table 2. Characteristics of the subjects

\begin{tabular}{lccc}
\hline & Group A $^{\text {a) }}$ & Group B $^{\text {b) }}$ & Group C $^{\text {c) }}$ \\
\hline Sex & & & \\
Male & 5 & 5 & 6 \\
Female & 5 & 3 & 4 \\
\hline Age (yr) & $53.6 \pm 22.7$ & $52.5 \pm 15.5$ & $42.7 \pm 14.2$ \\
Height (cm) & $163.2 \pm 9.1$ & $167.7 \pm 12.1$ & $170.8 \pm 6.21$ \\
Weight (kg) & $62.4 \pm 8.26$ & $64.9 \pm 11.2$ & $66.9 \pm 8.1$ \\
AS score & & & \\
Ankle PF & $1.35 \pm 0.67$ & 0 & 0 \\
Knee flexor & $1.55 \pm 0.94$ & 0 & 0 \\
\hline
\end{tabular}

Values are presented as number or mean \pm standard deviation.

AS, original Ashworth Scale; PF, plantar flexor.

${ }^{a)}$ Patient with spinal cord injury and spasticity. ${ }^{\text {b) }} \mathrm{Pa}$ tient with spinal cord injury and no spasticity. ${ }^{\mathrm{c}}$ Healthy adults.

\section{Method}

We applied the ARFI technique and measured the SWV of the GCM and the BFLH. We used the AS to assess the spasticity of the ankle and knee joints.

\section{ARFI technique}

The examination started with a conventional ultrasound followed by ARFI. One experienced physician performed examination with a ACUSON S2000 ultrasound system (Siemens Healthcare, Erlangen, Germany) with linear probes (9L4). The positioning of the patients for imaging was identical to that used for standard clinical scanning. Scans of the short axis of the GCM and BFLH were performed with minimal compression applied with the transducer weight, bilaterally.

Three trials of ARFI imaging were performed and the mean of 3 SWVs was used. All subjects were scanned on an examination platform in the prone position with feet hanging over the edge. Ultrasound were repeatedly performed at the fixed point of the medial GCM, which was located at the middle of 2 reference points ( 1 point was located at the proximal one third of a longitudinal line from midway between the medial and lateral malleoli to midway between the medial and lateral epicondyles; the other point was located at the medial end on a transverse line perpendicular to the point on the longitudinal line) and performed at the BFLH, which was located at the midpoint between ischial tuberosity and lateral condyle of tibia. Scanning was discontinued whenever reflexive or voluntary contraction of the lower limb muscles was visually apparent. The target muscle was displayed in Bmode and the region of interest (ROI) was subsequently identified in the muscle. ARFI technology uses shortduration acoustic radiation forces to generate localized tissue displacement, which results in shear-wave propagation [7]. The ROI is characterized by a box with a fixed dimension of $0.5 \mathrm{~cm}^{2}$ for ARFI measurements during real-time B-mode imaging. The shear waves propagate perpendicular to the acoustic pulse, away from the target ROI. The velocity of the shear wave speed is expressed in m/s (Fig. 1).

\section{Assessment of spasticity}

The spasticity of the ankle plantar flexor muscles in patients with spasticity was measured as the degree of resistance to passive movement felt by the physical therapist 

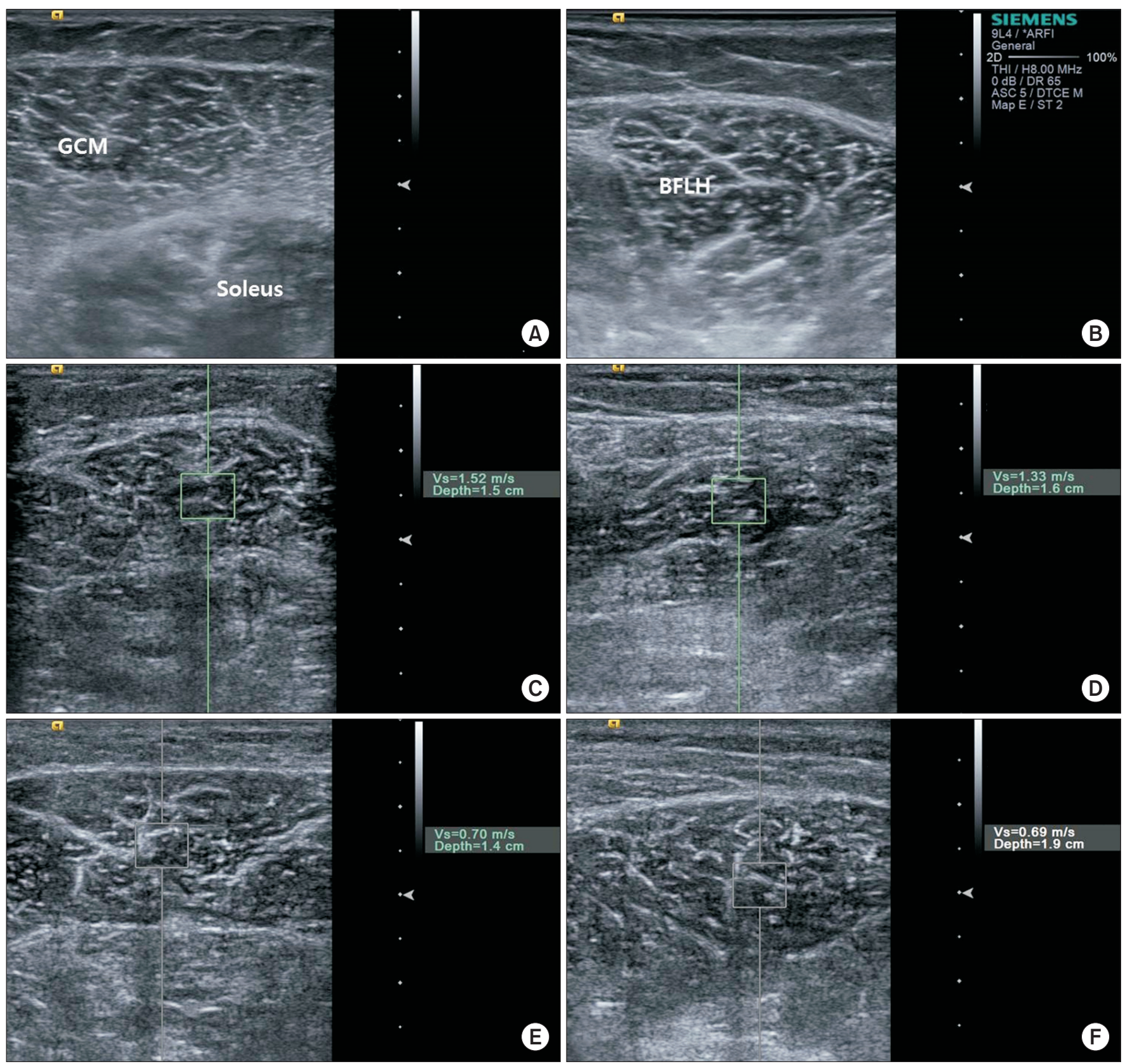

Fig. 1. B-mode ultrasound image of medial gastrocnemius (GCM) (A) and the long head of biceps femoris (BFLH) muscle (B). Shear wave velocity of medial GCM and the BFLH with spasticity (C, D) and without spasticity (E, F).

using the AS, with a rating from 0 to 4 (0, hypotonic; 4 , extreme resistance).

\section{Statistical analysis}

One-way analysis of variance (ANOVA) was used for comparison of SWV among the 3 groups (patients with spasticity, patients without spasticity and healthy sub- jects), whereas Tukey Honestly Significant Difference (HSD) was used for multiple comparisons. Betweengroup comparisons for continuous data were assessed with Mann-Whitney U test when appropriate. We evaluated correlation of spasticity with SWV by assessing the Spearman rank correlation coefficients. The interclass correlation coefficient was used to examine intra-rater 
reliability of repeated ARFI.

Data were expressed as the mean \pm standard deviation. Statistical significance was set at $\mathrm{p}<0.05$. All statistical tests were conducted using the SPSS ver. 18.0 (SPSS Inc., Chicago, IL, USA).

\section{RESULTS}

\section{SWV}

Patients with spasticity had significantly faster SWV for GCM and BFLH than those without spasticity (MannWhitney $U$ test, $\mathrm{p}=0.007$ and $\mathrm{p}=0.008$ ) and normal control ( $\mathrm{p}=0.011$ and $\mathrm{p}=0.037$, respectively) (Fig. 2). The SWVs of the GCM $(1.15 \pm 0.45 \mathrm{~m} / \mathrm{s})$ and BFLH $(1.43 \pm 0.76 \mathrm{~m} / \mathrm{s})$ in spastic patients was significantly higher, as compared with that of patients without spasticity (GCM, $0.66 \pm 0.08$

(A)

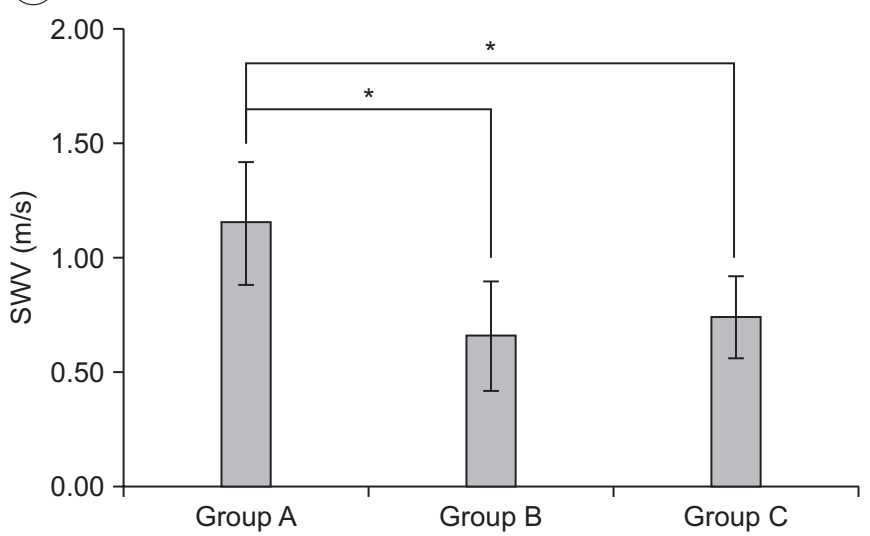

$\mathrm{m} / \mathrm{s} ; \mathrm{BFLH}, 0.73 \pm 0.19 \mathrm{~m} / \mathrm{s}$ ) and healthy subjects (GCM, $0.74 \pm 0.13 \mathrm{~m} / \mathrm{s}$; BFLH, $0.77 \pm 0.18 \mathrm{~m} / \mathrm{s})$. Interclass correlation coefficient for GCM was 0.85 and interclass correlation coefficient for BFLH was 0.79 , respectively.

\section{Correlation between SWV and spasticity}

The SWV values for the GCM correlated with ankle spasticity (Spearman rank test, $\mathrm{p}=0.026$ ). There were significant correlations between the SWV values for the long head of biceps femoris muscle and knee spasticity (Spearman rank test, $\mathrm{p}=0.022$ ) (Table 3).

\section{DISCUSSION}

We examined the correlation between the speed of the SWV and spasticity in patients with SCI. We assumed that

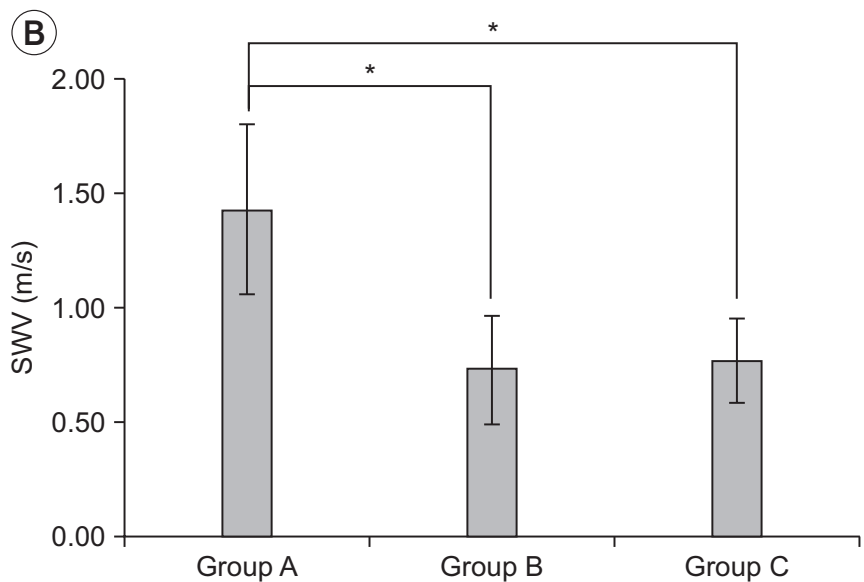

Fig. 2. Shear wave velocity (SWV) of medial gastrocnemius muscle (A) in 3 groups and the long head of biceps femoris muscle (B) in 3 groups. *p<0.05 in Mann-Whitney U test.

Table 3. Correlation of spasticity and SWV

\begin{tabular}{llcccc}
\hline & & SWVs of GCM & AS score of ankle & SWVs of BFLH & AS score of knee \\
\hline SWVs of GCM & $\mathrm{r}$ & 1 & - & - & - \\
AS score of ankle & $\mathrm{p}$ & - & - & - & - \\
& $\mathrm{r}$ & $0.498^{*}$ & 1 & - & - \\
SWVs of BFLH & $\mathrm{p}$ & 0.026 & - & - & - \\
& $\mathrm{r}$ & 0.239 & 0.354 & 1 & - \\
AS score of knee & $\mathrm{p}$ & 0.309 & 0.126 & - & - \\
& $\mathrm{r}$ & 0.086 & $0.470^{*}$ & $0.510^{*}$ & 1 \\
\hline
\end{tabular}

SWV, shear wave velocity; GCM, gastrocnemius muscle; AS, original Ashworth Scale; BFLH, long head of biceps femoris muscle.

${ }^{*} \mathrm{p}<0.05$ by Spearman rho test. 
the SWV of spastic muscle would be fast, as compared with patients without spasticity, these assumptions were established based on the knowledge that the SWV reflects the extent of hardness or stiffness, because GCM and BFLH in patients with spasticity become hard and stiff $[8,10,12,26,27]$. The SWVs of the BFLH and GCM with spasticity in patients who had SCI were statistically significantly faster, as compared with healthy adults. This result indicated that spastic muscle was hard and stiff, as compared with non-spastic muscles, because SWV is proportionate to tissue hardness. These findings supported the hypothesis that the degree of elasticity of tissue changes after SCI and the muscles become stiffer in SCI patients who have spasticity.

Our findings were consistent with other studies, which found that the degree of ankle spasticity was correlated with stiffness of the medial GCM in children with spastic cerebral palsy [28]. The SWV of the GCM in the group with spastic cerebral palsy was significantly higher than that in the group without neurologic and musculoskeletal disabilities [28].

We found a statistically significant positive correlation between SWVs and the AS score of spastic muscles. This indicated that SWV is fast when spasticity is high. Many studies reported that the total amount of collagen content and expression of genes that are involved in the conversion of collagen from the tissue, such as LH2b and TGF$\beta 1$ were increased in spastic muscle; and muscle fiber type transformation was observed in the post SCI patient group [29-31]. Based on these studies, we could predict that the degree of stiffness was increased in spastic muscle and we can measure the spasticity by SWV with ARFI, indirectly.

Most research on skeletal muscle spasticity has focused on the neural changes. It is reasonable because the primary cause leading to spasticity is located in the central nervous system [12]. In our study, 3 patients who had SCI showed low $\operatorname{SWV}(0.72,0.71$, and $0.65 \mathrm{~m} / \mathrm{s})$ although they had spasticity (AS grade of GCM was 1 and 2). Muscle and neural changes are usually related, but probably to differing extents, depending on the particular disease state, patient age, and time since injury. We thought that 3 patients had more neural changes, such as neurally mediated reflex stiffness, and less structural change. The other 7 patients showed high SWV in spastic GCM and BFLH that may be reflect more structural change such as stiffness and hardness than neural changes.

Scelsi [31] reported that muscle atrophy and muscle fiber type transformation in their fundamental properties occur in early SCI supporting the presence of progressive changes in muscles probably occurring early after cord injury. In our study, the ARFI-SWV values of spastic muscle were estimated as high in the early stage of SCI. This result indicating that increased muscle stiffness could occur at early stages post SCI was consistent with the previous study.

A greater number of test subjects will be required in future studies to evaluate spasticity by SWV adding to AS, the continuous variables (e.g., Spinal Cord Assessment Tool for Spastic Reflexes) as an accessory measurement of spasticity for neural and structural change in SCI patients.

ARFI is a convenient tool and has the advantage of being able to quantify the structural change such as stiffness and hardness of the tissue by measuring the SWV. It will therefore be a useful tool to measure the degree of stiffness of muscles with spasticity. Guzman-Aroca et al. [32] noted that SWV measured by ARFI has high intraexaminer reliability and high reproducibility.

Our study had limitations. Firstly, the number of subjects was small so statistical power was low and we were not able to perform a double-blind study to evaluate spasticity by the AS score and ARFI. Secondly, it was not possible to examine the relationship between the change in hardness and elasticity of the muscles and disease duration because SCI patients in our study were diagnosed within 3 months. Finally, only 1 observer performed 1 session for each compression condition. More investigations are needed to establish the inter-observer reliability of the SWV measurements.

However, this study is the first study to investigate spastic muscles in SCI patients using ARFI and SWV detection and evaluate correlation between the SWV values and spasticity in SCI patients. It has not been conducted in other clinical studies.

We focused on reducing muscle stiffness by stretching for treatment of the spasticity especially on muscle with estimated high SWV via ARFI. Further study with a larger sample size and an evaluation of the correlation between the SWV of muscle and the disease period of SCI is needed to confirm the validity of these study results.

In conclusion, this study proves the feasibility of quan- 
tifying spastic muscle stiffness with ARFI in SCI patients. ARFI demonstrated a difference in muscle stiffness between patients with spasticity and those without spasticity in SCI. These findings suggested that stiffness of muscles could be increased in spastic lower extremity of early SCI patients as well as chronic SCI patients.

ARFI imaging performed by an expert physiatrist is a valuable tool that can be used to noninvasively evaluate the spasticity of the muscle in SCI patients with AS. Furthermore, it has the potential to identify structural changes of the tissue associated with spasticity.

\section{CONFLICT OF INTEREST}

No potential conflict of interest relevant to this article was reported.

\section{REFERENCES}

1. Frigon A, Rossignol S. Functional plasticity following spinal cord lesions. Prog Brain Res 2006;157:231-60.

2. Elbasiouny SM, Moroz D, Bakr MM, Mushahwar VK. Management of spasticity after spinal cord injury: current techniques and future directions. Neurorehabil Neural Repair 2010;24:23-33.

3. Abbruzzese G. The medical management of spasticity. Eur J Neurol 2002;9 Suppl 1:30-4.

4. Adams MM, Hicks AL. Spasticity after spinal cord injury. Spinal Cord 2005;43:577-86.

5. Decq P. Pathophysiology of spasticity. Neurochirurgie 2003;49(2-3 Pt 2):163-84.

6. Dietz V, Sinkjaer T. Spastic movement disorder: impaired reflex function and altered muscle mechanics. Lancet Neurol 2007;6:725-33.

7. Hufschmidt A, Mauritz KH. Chronic transformation of muscle in spasticity: a peripheral contribution to increased tone. J Neurol Neurosurg Psychiatry 1985;48:676-85.

8. Gracies JM. Pathophysiology of spastic paresis. I. Paresis and soft tissue changes. Muscle Nerve 2005;31:53551.

9. O'Dwyer NJ, Ada L, Neilson PD. Spasticity and muscle contracture following stroke. Brain 1996;119(Pt 5):1737-49.

10. Dietz V, Ketelsen UP, Berger W, Quintern J. Motor unit involvement in spastic paresis: relationship between leg muscle activation and histochemistry. J Neurol Sci 1986;75:89-103.

11. Edstrom L. Selective changes in the sizes of red and white muscle fibres in upper motor lesions and Parkinsonism. J Neurol Sci 1970;11:537-50.

12. Lieber RL, Steinman S, Barash IA, Chambers H. Structural and functional changes in spastic skeletal muscle. Muscle Nerve 2004;29:615-27.

13. Nightingale K, McAleavey S, Trahey G. Shear-wave generation using acoustic radiation force: in vivo and ex vivo results. Ultrasound Med Biol 2003;29:1715-23.

14. Palmeri ML, Wang MH, Dahl JJ, Frinkley KD, Nightingale KR. Quantifying hepatic shear modulus in vivo using acoustic radiation force. Ultrasound Med Biol 2008;34:546-58.

15. Meng W, Zhang G, Wu C, Wu G, Song Y, Lu Z. Preliminary results of acoustic radiation force impulse (ARFI) ultrasound imaging of breast lesions. Ultrasound Med Biol 2011;37:1436-43.

16. Stock KF, Klein BS, Vo Cong MT, Sarkar O, Romisch M, Regenbogen C, et al. ARFI-based tissue elasticity quantification in comparison to histology for the diagnosis of renal transplant fibrosis. Clin Hemorheol Microcirc 2010;46:139-48.

17. Bota S, Sporea I, Sirli R, Popescu A, Danila M, Sendroiu M, et al. Spleen assessment by Acoustic Radiation Force Impulse Elastography (ARFI) for prediction of liver cirrhosis and portal hypertension. Med Ultrason 2010;12:213-7.

18.Zhai L, Polascik TJ, Foo WC, Rosenzweig S, Palmeri ML, Madden J, et al. Acoustic radiation force impulse imaging of human prostates: initial in vivo demonstration. Ultrasound Med Biol 2012;38:50-61.

19. D’Onofrio M, Gallotti A, Martone E, Pozzi Mucelli R. Solid appearance of pancreatic serous cystadenoma diagnosed as cystic at ultrasound acoustic radiation force impulse imaging. JOP 2009;10:543-6.

20. D'Anastasi M, Schneevoigt BS, Trottmann M, Crispin A, Stief C, Reiser MF, et al. Acoustic radiation force impulse imaging of the testes: a preliminary experience. Clin Hemorheol Microcirc 2011;49:105-14.

21. Friedrich-Rust M, Romenski O, Meyer G, Dauth N, Holzer K, Grunwald F, et al. Acoustic radiation force impulse-imaging for the evaluation of the thyroid gland: a limited patient feasibility study. Ultrasonics 2012;52:69-74. 
22. Kot BC, Zhang ZJ, Lee AW, Leung VY, Fu SN. Elastic modulus of muscle and tendon with shear wave ultrasound elastography: variations with different technical settings. PLoS One 2012;7:e44348.

23. Friedrich-Rust M, Wunder K, Kriener S, Sotoudeh F, Richter S, Bojunga J, et al. Liver fibrosis in viral hepatitis: noninvasive assessment with acoustic radiation force impulse imaging versus transient elastography. Radiology 2009;252:595-604.

24. Palmeri ML, Wang MH, Rouze NC, Abdelmalek MF, Guy CD, Moser B, et al. Noninvasive evaluation of hepatic fibrosis using acoustic radiation force-based shear stiffness in patients with nonalcoholic fatty liver disease. J Hepatol 2011;55:666-72.

25. Shen ZL, Vince DG, Li ZM. In vivo study of transverse carpal ligament stiffness using acoustic radiation force impulse (ARFI) imaging. PLoS One 2013;8:e68569.

26. Akagi R, Chino K, Dohi M, Takahashi H. Relationships between muscle size and hardness of the medial gastrocnemius at different ankle joint angles in young men. Acta Radiol 2012;53:307-11.

27. Arda K, Ciledag N, Aktas E, Aribas BK, Kose K. Quantitative assessment of normal soft-tissue elasticity using shear-wave ultrasound elastography. AJR Am J Roentgenol 2011;197:532-6.

28. Kwon DR, Park GY, Lee SU, Chung I. Spastic cerebral palsy in children: dynamic sonoelastographic findings of medial gastrocnemius. Radiology 2012;263:794-801.

29. Booth CM, Cortina-Borja MJ, Theologis TN. Collagen accumulation in muscles of children with cerebral palsy and correlation with severity of spasticity. Dev Med Child Neurol 2001;43:314-20.

30. Gagliano N, Pelillo F, Chiriva-Internati M, Picciolini O, Costa F, Schutt RC Jr, et al. Expression profiling of genes involved in collagen turnover in tendons from cerebral palsy patients. Connect Tissue Res 2009;50:203-8.

31. Scelsi R. Skeletal muscle pathology after spinal cord injury: our 20 year experience and results on skeletal muscle changes in paraplegics, related to functional rehabilitation. Basic Appl Myol 2001;11:75-85.

32. Guzman-Aroca F, Reus M, Berna-Serna JD, Serrano L, Serrano C, Gilabert A, et al. Reproducibility of shear wave velocity measurements by acoustic radiation force impulse imaging of the liver: a study in healthy volunteers. J Ultrasound Med 2011;30:975-9. 